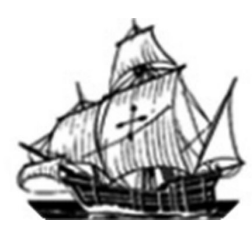

Nau Literária: crítica e teoria de literaturas • seer.ufrgs.br/NauLiteraria

ISSN 1981-4526・PPG-LET-UFRGS • Porto Alegre • vol. 09, n. 01 • jan/jun 2013

Dossiê: Voz e Interculturalidade

\title{
PECULIARES E RESISTENTES: RELATOS ORAIS E CANÇÃO DAS TRIBOS CARNAVALESCAS DE PORTO ALEGRE
}

\section{Jackson Raymundo}

Resumo: O índio tematizado por negros (e brancos da periferia) numa manifestação artística que é símbolo de "brasilidade": estas são as tribos carnavalescas, motivo deste artigo. Com trajetória semelhante às escolas de samba, as tribos são uma peculiaridade do carnaval de Porto Alegre. Surgiram entre os anos 1940 e 1950, num contexto de afirmação do negro dentro da "identidade nacional" e de sua busca pela aceitação social. A pesquisa registrou relatos orais de componentes das tribos e recorreu a documentos e publicações que abordam a temática indígena na cultura brasileira, assim como o negro e o carnaval na capital gaúcha. Por fim, a apresentação fala sobre o hino, a canção própria das tribos carnavalescas de Porto Alegre.

Palavras-chave: Tribos carnavalescas, Canção popular brasileira, Carnaval, Indianismo, Perspectivismo ameríndio

ABSTRACT: The Indian themed by blacks (and whites of the periphery) in an artistic expression that's symbol of "Brazilianness". With similar trajectory to the samba schools, the "tribos" (tribes) are a peculiarity of the Carnival of Porto Alegre, in southern Brazil. Emerged between the 1940s and 1950s, in the context of affirmation of Black within the "national identity" and their quest for social acceptance. The survey recorded oral reports of components of the tribes and resorted to documents and publications that address indigenous issues in Brazilian culture, as well as the Black and carnival in Porto Alegre. Finally, the presentation addresses the hino (anthem), the song of the tribes own carnival.

Keywords: tribes carnival, Brazilian Popular song, Indianism, Amerindian pespectivism

* Mestrando em Letras-Literatura Brasileira/UFRGS. E-mail: jacksonraymundo@yahoo.com.br 


\section{Introdução}

O carnaval brasileiro tornou-se uma das principais marcas identitárias do país, um dos símbolos mais conhecidos daquilo que se convencionou chamar de brasilidade. Mas é insuficiente tratar o carnaval como um acontecimento uno, homogêneo: muitos são os carnavais que mobilizam o país e expressam a sua diversidade cultural. Além das escolas de samba, provavelmente o gênero carnavalesco mais conhecido, há os blocos, os trios elétricos, os clubes, as tribos carnavalescas etc. (é importante ainda destacar os ranchos e cordões, hoje praticamente extintos, mas de onde veio parte das características das atuais agremiações).

Esta apresentação irá tratar das tribos carnavalescas, uma peculiaridade do carnaval de Porto Alegre, e da sua canção, o hino. O trabalho é produto de pesquisa desenvolvida para a disciplina "Teoria e Crítica da Literatura Brasileira" (Programa de Pós-Graduação em Letras/UFRGS), ministrada pelo professor Luís Augusto Fischer no primeiro semestre de 2013. Dentro do desafio proposto pela disciplina, apresentado no subtítulo "Um modelo para a história da literatura brasileira e talvez americana: entre Idéias fora do lugar e Perspectivismo ameríndio", a pesquisa teve por objetivo conhecer e aprofundar o que era essa manifestação artística de caráter urbano e popular, com uma canção própria (e gênero lítero-musical próprio), onde o índio é o centro (qual índio? Como ele é apresentado? Quem são as pessoas que fazem as tribos carnavalescas? Quais e como são as histórias contadas? etc).

Como método, recorreu-se a publicações sobre a temática indígena na cultura brasileira e continental, de forma especial ao perspectivismo ameríndio; a estudos sobre o negro no século XX, destacadamente em Porto Alegre e no Rio Grande do Sul; a publicações sobre o samba e o carnaval; e a relatos orais e depoimentos colhidos in loco junto a componentes da tribo Os Comanches.

O estudo sobre o hino, a canção própria das tribos carnavalescas, abordará as características lítero-musicais que fazem o gênero, e como as tribos de Porto Alegre

* Mestrando em Letras-Literatura Brasileira/UFRGS. E-mail: jacksonraymundo@yahoo.com.br 
influenciariam outros gêneros, como o suingue/samba-rock. Para isso, contou-se com letras disponibilizadas por integrantes d'Os Comanches, gravações em CDs e materiais na internet.

\section{O negro e o índio, o carnaval e o nacionalismo}

O surgimento das escolas de samba, entre fins dos anos 1920 e os 1930, significou um passo importante para a aceitação social do povo negro e das classes populares urbanas. A partir do Rio de Janeiro, as escolas de samba espalharam-se pelo Brasil nas décadas seguintes, até se tornarem a face mais visível e conhecida do “carnaval brasileiro". Em pouco tempo foram legitimidas (e parcialmente financiadas) pelo poder público, num contexto de Estado Novo e de busca da "integração nacional".

As escolas de samba desde os seus primórdios estiveram comprometidas com a construção de uma "nacionalidade" e "brasilidade". Além disso, o próprio termo "escola", criado por sambistas do morro do Estácio, traria a ideia de organização ao até então desordeiro carnaval de rua:

[...] é curioso que a ênfase dada ao "nacional" e ao "brasileiro" venha das escolas, que já percebiam que estavam agradando e até sendo usadas para propaganda turística. No documento de 1935, o samba ganha foros de "verdadeira música nacional" e se enfatiza seu "cunho essencial de brasilidade", a par com "todo o esplendor de sua originalidade". Os objetivos da União das Escolas incluíam a realização de "cortejos baseados em motivos nacionais", com o que estariam "fazendo ressurgir o Carnaval de rua". [...] o novo folguedo é são e ordeiro - aliás, como o novo apelativo, escola de samba, ressalta. (GALVÃO, 2009, p. 45)

Paradoxalmente, essa "nacionalidade", que nas escolas de samba era representada/produzida por negros e cidadãos da periferia urbana, não incluía dois dos elementos principais na formação étnica brasileira: o próprio negro e o índio.

Por muito tempo vigorou no Rio de Janeiro a obrigatoriedade de "temas pátrios" - outra decisão dos sambistas, a fim de angariar o apoio do poder público. Essa obrigatoriedade fundou uma característica nos enredos: falar dos grandes "vultos históricos" e episódios da História do Brasil. No entanto, esses "vultos" e essa "História" eram praticamente só de brancos (e das elites) naquelas primeiras décadas

* Mestrando em Letras-Literatura Brasileira/UFRGS. E-mail: jacksonraymundo@yahoo.com.br 
de existência das escolas de samba. Isso só começaria a mudar na virada da década de 1960, quando a temática negra enfim se torna enredo das escolas de samba.

No projeto de "nação" de Vargas, o negro era basilar. Para Amauri de Souza (PEREIRA, 2003), “os negros e mulatos eram, na realidade, a componente principal do povo que Vargas transformou, de cidadãos de segunda classe em um dos principais suportes do Estado Novo". Dentre os avanços promovidos pelo governo de Vargas, estão a legislação trabalhista e a Lei dos $2 / 3$, em que de cada três trabalhadores, dois tinham de ser brasileiros.

Já o índio, no carnaval carioca continuaria secundarizado, tendo apenas presenças esporádicas nos desfiles.

A contextualização feita a partir do Rio de Janeiro auxilia a compreender o carnaval de Porto Alegre. Mas é comparando que saltam diferenças interessantes.

Porto Alegre, capital e metrópole em seu Estado, mas província em relação à então capital da República, importaria o modelo de escolas de samba do carnaval de rua do Rio de Janeiro, mas somente no início dos anos 1960, com a pioneira Praiana. Antes disso, os festejos momescos eram formados por blocos (vários deles se converteriam em escolas de samba) e por outros grupos carnavalescos, como as tribos.

A ascensão de Vargas e de uma grande leva de gaúchos ao poder central, em 1930, acarretaria mudanças na relação do Rio Grande do Sul com o Brasil e a "brasilidade". A "identidade nacional" significaria a aceitação para os negros marginalizados de seus direitos básicos. Nessa busca da brasilidade, o carnaval tinha importância considerável, segundo Germano (2010):

\begin{abstract}
No contexto dos anos 30, o gaúcho Getúlio Vargas subia ao poder central, enfocando a brasilidade do Rio Grande do Sul, mostrando que o estado possuía carnaval e mulatos, justificando assim sua brasilidade. Negociação estratégica porque pertencer à identidade nacional era uma fonte de colocarse como parte de uma identidade aceita e incentivada, a de uma identidade africanizada, constantemente criticada. Essa atitude garantia recursos financeiros do poder público e a possibilidade de continuar "brincando" o carnaval sem ser criticado. (GERMANO, 2010, p. 116)
\end{abstract}

E o índio?

Quando se falava de integração nacional e da identidade mestiça do povo brasileiro, o indígena estava incluído. Assim como o negro, o índio também era parte do triângulo das três raças, praticamente uma linha política do Estado Novo e conceito largamente trabalhado por autores como Gilberto Freyre.

* Mestrando em Letras-Literatura Brasileira/UFRGS. E-mail: jacksonraymundo@yahoo.com.br 
O contraste das três raças na obra de Freyre é assim sintetizado pelo antropólogo Eduardo Viveiros de Castro:

A antropologia racialista de Gilberto Freyre reservou ao contraste entre o vigor animal dos africanos e a preguiça vegetal dos ameríndios um papel de destaque. [...] O tema das "três raças" na formação da nacionalidade brasileira tende a atribuir a cada uma delas o predomínio de uma faculdade: aos índios a percepção, aos africanos o sentimento, aos europeus a razão [...] (VIVEIROS DE CASTRO, 2011, p. 187)

É neste contexto de busca da "nacionalidade", que marcava o Brasil nos anos 1930 e 40, que habitantes da periferia de Porto Alegre criam as tribos carnavalescas. Em 19 de abril de 1945, Dia do Índio, surgia a tribo Caetés, e anos depois, o primeiro concurso de tribos carnavalescas. Elas chegaram a ser maioria nos anos 1950, mas, com a crescente hegemonia das escolas de samba, entraram em decadência nos anos 70. Restam hoje apenas duas, Os Comanches e Guaianazes.

A fundação das tribos carnavalescas se dava dentro da compreensão de que era o índio "o verdadeiro dono na nacionalidade" (GERMANO, 1999). Sendo assim, era natural que também no carnaval o índio, o "dono" desta terra, fosse tematizado de forma permanente em histórias, figurinos, cenários, canção. E quem idealizaria isso não era o branco dos bairros ricos, mas o negro e o branco (e miscigenado) da periferia.

\begin{abstract}
O que chama a atenção nessa identificação do negro com o índio é que tanto um quanto o outro eram elementos excluídos e marginalizados na sociedade brasileira e no imaginário local. No entanto, a representação do índio simbolizando a identidade nacional nos anos 30 e 40 estava de acordo com o triângulo das três raças, proposto pelos teóricos da cultura nacional. Por isso, essa identificação com o índio brasileiro pode também ser interpretada como uma forma de o negro reivindicar sua cidadania e identidade nacional, identificando-se com um elemento associado de forma positiva à identidade brasileira. [...] o negro era associado a representações positivas quando era exaltado seu caráter popular, brasileiro, mulato, miscigenado, expresso nos sambas e nos gingados. A representação do africano, contrariamente, era associada a um elemento menos brasileiro, distante do samba e do mulato, culturalmente atrasado, em meio aos seus ruídos carnavalescos. (GERMANO, 1999, p. 146)
\end{abstract}

Para situar, é importante apresentar mais alguns elementos do carnaval em Porto Alegre: as escolas de samba são compostas majoritariamente pelo povo negro, com escassa presença da população branca. A apropriação do carnaval pelos negros e

* Mestrando em Letras-Literatura Brasileira/UFRGS. E-mail: jacksonraymundo@yahoo.com.br 
o conjunto das classes populares ocorre nos anos 1930 e 1940, quando o samba e o carnaval se tornam "símbolos nacionais" e se crê em uma nação "miscigenada".

Quando se fala de etnicidade no Rio Grande do Sul, cabe destacar a construção feita ao longo do século XX da figura do gaúcho. Em consonância com a ideia de uma "democracia racial" brasileira, fundamentou-se a "democracia racial dos pampas". O protótipo do gaúcho seria o homem dos pampas, mais tarde agregando também o imigrante europeu (alemão e italiano). O negro e o índio andariam sempre à margem do sentido de "gauchidade", atuando como coadjuvantes ou mero figurantes.

Para se integrar à essa "democracia racial" branca e da cidade, os negros criaram seus próprios símbolos e formas de organização cultural, política e comunitária. A cultura negra, trazida de diferentes lugares da África e recriada na realidade brasileira, conseguiu dialogar com as culturais locais e interagir com elas, criando novos significados e sínteses.

A cultura negra participou e dialogou com a realidade branca, mantendo viva sua história particular, que somente tem sentido para aquele que compartilha de determinados significados atribuídos aos símbolos, que são continuamente retransmitidos de geração a geração e que extrapolam os limites do regional ou do nacional para se explicarem.

A cultura negra sempre dialogou com culturas e costumes produzidos no mundo inteiro, absorvendo inúmeras tradições locais, regionais ou nacionais, ressignificando-as continuamente. (GERMANO, 2010, p. 117-118)

Viveiros de Castro (2011, p. 209), ao definir o que é cultura, expõe argumento semelhante: "uma cultura não é um sistema de crenças, mas antes - já que deve ser algo - um conjunto de estruturações potenciais da experiência, capaz de suportar conteúdos tradicionais e absorver novos".

Esse diálogo e essa centrifugação de culturas e tradições é visível na religiosidade, onde os deuses (orixás) das religiões de matriz africana sincretizam com santos católicos e figuras indígenas, como os caboclos. A relação com a vida e o sagrado é semelhante nos cultos africanos e indígenas. Como diz Avancini (2010, p. 138), "na cultura dos povos africanos à chegada dos europeus no continente, o sagrado não se distinguia da vida profana como nas práticas religiosas do mundo ocidental. Tudo é sagrado. A vida é sagrada. A palavra é sagrada.” (p. 138)

O perspectivismo ameríndio de Viveiros de Castro é estratégico para a compreensão dessa e das demais relações da vida com o sagrado, e da inter-relação

* Mestrando em Letras-Literatura Brasileira/UFRGS. E-mail: jacksonraymundo@yahoo.com.br 
entre os seres. Principalmente no Brasil e na América Latina, onde os indígenas já foram os "donos da terra" e ainda existem em grande número (e serem ascendentes de grande parte da população), estudar aspectos da sociedade à luz da visão de mundo indígena - ou "ameríndia" - parece-me um caminho instigante e recomendável para certos casos.

A etnologia indígena trabalhada por Viveiros de Castro pretende "alargar o mundo dos possíveis humanos, mostrando que a tradição cultural europeia não detém, nem de fato nem de direito, o monopólio do pensamento" (SZUTMAN, 2008, p. 79). A cosmovisão ameríndia traz pontos de vista bastante distintos do olhar ocidental, como explica o antropólogo, em entrevista:

“[...] o modo como os seres humanos veem os animais e outras subjetividades que povoam o universo - deuses, espíritos, mortos, habitantes de outros níveis cósmicos, plantas, fenômenos meterológicos, acidentes geográficos, objetos e artefatos - é profundamente diferente do modo como esses seres veem os humanos e se veem a si mesmos." (SZUTMAN, 2008, p. 350)

Assim, o perspectivismo ameríndio apresenta-se, em vez de relativista e multiculturalista, como relacionista e multinaturalista.

O relativismo cultural, um multiculturalismo, supõe uma diversidade de representações subjetivas e parciais, incidentes sobre uma natureza externa [...]; os ameríndios propõem o oposto: uma unidade representativa ou fenomenológica puramente pronominal, aplicada indiferentemente sobre uma diversidade real. Uma só cultura, múltiplas "naturezas" [...] o perspectivismo é um multinaturalismo, pois uma perspectiva não é uma representação. (VIVEIROS DE CASTRO, 2011, p. 379)

\section{Identidade, “autenticidade", histórias}

As tribos carnavalescas de Porto Alegre nascem, como já foi dito, num contexto de construção de uma "identidade nacional". Sendo assim, poderia se supor um nacionalismo exacerbado destas agremiações, à la Policarpo Quaresma. Mas não é o que ocorre. Os nomes escolhidos para as tribos não necessariamente eram de comunidades indígenas brasileiras. Nem o nome de suas sedes, chamadas de "tabas", precisava ter relação com a tribo que dava título à agremiação.

Para ficar no exemplo d'Os Comanches, que visitei durante a pesquisa: os comanches são um grupo étnico do sul dos Estados Unidos e que aqui ficou conhecido pelos filmes western e pelas revistas em quadrinhos Tex Willer. Valdir Ribeiro, atual

* Mestrando em Letras-Literatura Brasileira/UFRGS. E-mail: jacksonraymundo@yahoo.com.br 
presidente e um dos fundadores da tribo carnavalesca em 1959, explicou que o primeiro nome escolhido foi "Os Tupis”. Mais tarde (não especificou quando), os integrantes, em votação, mudaram para "Os Comanches". "Seu Valdir" assumiu que a inspiração veio do cinema americano, ressaltando que a sua tribo foi a primeiro a optar por indígenas estrangeiros. A sede dos Comanches é a “Taba de Urupá”. Questionado de onde surgiu o nome, Seu Valdir disse que "veio de um livro" (os urupás são uma comunidade indígena de Rondônia, inclusive com uma língua própria. Dá nome a um município naquele Estado).

As tribos carnavalescas já foram 17 em Porto Alegre. Num panorama geral, percebem-se as mais diversas procedências. Os carnavalescos gaúchos se inspiraram tanto em etnias conhecidas no país, como os guaranis, mas também em grupos indígenas menos numerosos, ou até extintos, como os guaianás (a tribo carnavalesca seria “Guaianazes”). Duas entidades levariam nomes de comunidades indígenas dos Estados Unidos - além dos Comanches, “Os Navajos”. Os indígenas do Rio Grande do Sul e do Uruguai também seriam lembrados.

\begin{tabular}{|c|c|}
\hline GRUPO INDÍGENA & LOCALIDADE(S) \\
\hline $\begin{array}{c}\text { Arachaneses } \\
\text { (Arachanes) }\end{array}$ & Leste do Uruguai e sul do Rio Grande do Sul \\
\hline Comanches & Sul dos EUA \\
\hline $\begin{array}{c}\text { Guaianazes } \\
\text { (Guaianás) }\end{array}$ & Serra do Mar, São Paulo \\
\hline Caetés & Pernambuco \\
\hline Xavantes & Mato Grosso \\
\hline Guaranis & Boarte da América do Sul \\
\hline Iracemas & (como não se trata de grupo indígena, provavelmente refere-se ao \\
& romance de José de Alencar) \\
\hline Tapuias & Ocupavam boa parte do Brasil Colonial. Hoje há grupo em Goiás. \\
\hline Bororós & Mato Grosso \\
\hline Aimorés & Bahia, Minas Gerais e Espírito Santo \\
\hline Navajos & Sudoeste dos EUA \\
\hline Rojaba & sem informações \\
\hline Tupinambás & Antepassados de todos as etnias tupi do Brasil. \\
\hline Charruas & Rio Grande do Sul, Uruguai e nordeste da Argentina \\
\hline Tapajós & Amazonas \\
\hline
\end{tabular}

* Mestrando em Letras-Literatura Brasileira/UFRGS. E-mail: jacksonraymundo@yahoo.com.br 
A quem porventura exigisse uma "identidade pura" das tribos carnavalescas, valeria recorrer a uma entrevista de Viveiros de Castro, conceituando o perspectivismo: "Todos os ameríndios compartilham de um velho fundo cultural comum, onde se radica, penso eu, o que chamei de perspectivismo" (SZUTMAN, 2008, p. 77).

A quem questionasse a "autenticidade", novamente o perspectivismo ajudaria a responder. Viveiros, em outra entrevista, contesta a ideia de "culturas autênticas" e ainda a pureza étnica: "Não há culturas inautênticas, pois não há culturas autênticas. Não há, aliás, índios autênticos. Índios, brancos, afro-descendentes, ou quem quer que seja - pois autêntico não é uma coisa que os humanos sejam" (SZUTMAN, 2008, p. $148)$.

Essa "inautenticidade" é um elemento importante no estudo das tribos de carnaval. Analisando os enredos dos últimos dez anos das duas agremiações remanescentes, verifica-se uma ampla variedade de temas, tempos e espaços: os incas peruanos, "da Sibéria ao México", o Cacique Seattle, os caingangues do norte do Rio Grande do Sul, os últimos índios charruas etc.

\section{TEMAS-ENREDO - Guaianazes}

- 2004 - Miralutu - Hélio Dias, o guerreiro da paz

- 2005 - A Grande Nação Xinguana.

- 2006 - A grande lenda da Missão do sangradouro do alto Xingu

- 2007- Nhanderuvuçu, o senhor da criação

- 2008 - Xatopi: A virgem virou flor

- 2009 - Da Sibéria ao México, a história de uma grande nação

- 2010 - Nação Inca Peruana

- 2011 - O clarão da lua cheia mistérios da força do amor

- 2012 - Wayana Apalai o Poder da Sete Forças

- 2013 - O Grande Tratado da Nação Xinguana

* Mestrando em Letras-Literatura Brasileira/UFRGS. E-mail: jacksonraymundo@yahoo.com.br 


\section{TEMAS-ENREDO - Os Comanches}

- 2004 - As palavras do cacique Seattle.

- 2005 - O Guerreiro Ubirajara conta: O amor foi mais forte

- 2006 - Dinaí, a princesa das águas

- 2007 - Uma história guarani.

- 2008 - A sentença de Águia Amarela

- 2009 - Os Comanches vem a Porto Alegre conhecer Caingangs e juntos comemoram 50 anos de avenida

- 2010 - A $1^{a}$ Missa na Ilha de Santa Cruz

- 2011 - A saga de um povo: os últimos índios charruas

- 2012 - O sonho de Paraguassu

- 2013 - Lenda do Muiraquitã

Quando questionada sobre o que motiva a tribo a escolher determinado tema, Karen Ribeiro, secretária-geral da agremiação e filha do Seu Valdir, é enfática: "aquilo que faz o coração bater mais".

Durante todo o ano a canção da tribo, chamada de hino, será entoada nos ensaios na Taba de Urupá, que ocorrem semanalmente, às sextas à noite, e intensificam-se no período pré-carnavalesco. Os desfiles acontecem no sambódromo do Porto Seco, antecedendo as escolas de samba (uma tribo por noite). Nele, Os Comanches levam entre 300 e 400 participantes, oriundos principalmente da comunidade na qual está situado, a Vila São José (bairro Partenon, zona leste de Porto Alegre), mas também de localidades vizinhas, como a Vila João Pessoa e a Lomba do Pinheiro. O trabalho é majoritariamente produzido pela equipe-família, mas cada ala tem a sua costureira. Indagados se há rivalidade com os integrantes dos Guaianazes, a tribo adversária, os Comanches respondem que sim, "mas só na avenida".

Muitas são as diferenças estéticas entre as tribos carnavalescas e as escolas de samba. Além da canção, que não é o samba-enredo, mas o hino, todos os integrantes

* Mestrando em Letras-Literatura Brasileira/UFRGS. E-mail: jacksonraymundo@yahoo.com.br 
da direção e as alas têm nome indígena, assim como as funções - caciques, guerreiros, pajés etc. No figurino, há o uso de sapatilhas, e não de sapatos; outros adereços comuns são penas, colares, cocares, flechas, lanças, escudos.

Outra diferença substancial para as escolas de samba está nos quesitos avaliados. Aliás, cabe ressaltar que os critérios de julgamento exercem papel fundamental para a compreensão do desfile das tribos carnavalescas enquanto manifestação artística. Elas preparam o seu espetáculo não apenas para se exibir folcloricamente, mas para vencer. Ainda que haja uma disparidade entre as duas tribos em número de títulos - enquanto os Guaianazes venceram quatro, Os Comanches contam com trinta campeonatos (no período entre 1997 e 2013, perdeu somente duas vezes), ambas entram como o intuito de "ganhar" o carnaval em sua particular disputa. Os quesitos do concurso de tribos são: bateria, harmonia, evolução, enredo, hino, alegorias, fantasia, encenação.

A encenação é outra forte peculiaridade. No meio do desfile, há uma interrupção e um ritual indígena é dramatizado. $\mathrm{O}$ ato deve encenar elementos do enredo, entoando, porém, outro canto e dançando em outro ritmo.

E onde se dá a busca pelas narrativas indígenas? Seu Valdir respondeu que em fontes diversas, tais como livros, filmes, revistas em quadrinhos, internet etc. Vale qualquer história, desde que tenha temática indígena.

Quanto à etnicidade dos membros da tribo Os Comanches, Seu Valdir e a filha Karen respondem que são principalmente negros, mas "é misturado". A presença de índios não é costumeira, e os dirigentes da entidade afirmaram não ter descendência indígena. Em 2009, porém, a entidade teve em seu desfile a presença do povo caingangue de Iraí, norte do Rio Grande do Sul, tema-enredo naquele ano.

Viveiros de Castro afirma, em entrevista, que há uma origem étnica (indígena) comum a todos os brasileiros:

\footnotetext{
"Eu direi que no Brasil todo mundo é índio, exceto quem não é. Acho que o problema é 'provar' quem não é índio no Brasil. [...]

O homem livre da ordem escravocrata é um índio, o caiçara é um índio, o caboclo é um índio, o camponês do interior do nordeste é um índio. Índio em que sentido? Ele é um índio genético, para começar, apesar disso não ter a menor importância" (SZUTMAN, 2008, p.146-147)
}

\section{Hino, a canção das tribos carnavalescas}

* Mestrando em Letras-Literatura Brasileira/UFRGS. E-mail: jacksonraymundo@yahoo.com.br 
A canção das tribos carnavalescas, o hino, deve representar em versos o enredo narrado pela agremiação (mesmo papel desempenhado pelo samba-enredo das escolas de samba). Os seus componentes devem cantar o hino ao longo da avenida, sob pena de a tribo perder pontos na avaliação.

No caso dos Comanches, os compositores geralmente são os mesmos, sendo que um deles é também ou intérprete. Não são moradores da comunidade na qual a tribo está inserida.

Um fato me chamou a atenção na pesquisa: a maior parte das canções se perdeu. Karen, filha de Seu Valdir, disse que a mãe Georgina, a matriarca e "faz tudo" da tribo, falecida em 2012, não guardava as letras, porque não seria "útil" - o importante sempre era pensar o próximo carnaval. No entanto, os seus integrantes continuam cantando os hinos antigos nos ensaios, tradição que se mantém pela oralidade.

As tribos carnavalescas influenciaram a formação de vários músicos gaúchos e a constituição de gêneros musicais como o suingue - a versão gaúcha do samba-rock. Junto com as escolas de samba, criariam uma música peculiar, conforme o musicólogo Mateus Berger Kuschik:

Juntamente com a iniciação musical dentro da escola de samba, outros espaços carnavalescos no entorno dessas instituições, em Porto Alegre, exerceram forte influência sobre a construção de uma música com peculiaridades rítmicas em relação a outros lugares do país. Esse cruzamento resultou em uma sonoridade própria, única [...] (KUSCHIK, 2013, p. 45-46)

As tribos preservariam elementos rítmicos próprios, como a levada do ziguiné, aponta o músico Nego Luis em vídeo documentado por Kuschik. Em seu depoimento, Nego Luis destaca o caráter distinto das tribos carnavalescas: Porque o único estado que tem no país isso daí é o Rio Grande do Sul, que
conserva esse negócio de índio. E é de índio, mesmo! O indio que é assim. Os caras
de lá usam, o Cacique de Ramos, mas é tipo escola. Aqui não, eles conservam o
negócio de indio. Mas foi morrendo porque saíam vários! Assim: os índios saíam
no sábado; no domingo, o humorismo, que era pra dar risada; e na segunda-feira
eram as escolas. [grifo do autor] (Nego Luis, 27.9.2010 apud KUSCHIK, 2013, p.
46)

Há uma característica adjetiva na canção das tribos que é marcante na literatura produzida em Porto Alegre e no Rio Grande do Sul: a melancolia. O professor e músico Adair Antunes, jurado no carnaval de 2013, escreve em sua justificativa de * Mestrando em Letras-Literatura Brasileira/UFRGS. E-mail: jacksonraymundo@yahoo.com.br 
nota para a tribo Os Comanches: "Letra e melodia fazem do trabalho musical um conjunto de qualidade. O tom menor deixou a música melancólica, que é o verdadeiro espírito da tribo carnavalesca. Merece a nota máxima." (BATICUMBUM, 21.02.2013)

Luís Augusto Fischer e Sérgio Luís Fischer (2006) percebem o traço da melancolia em dois dos maiores poetas gaúchos (e brasileiros): Mário Quintana e Lupicínio Rodrigues. Apesar de terem sido contemporâneos por bastante tempo, não se encontraram "produtivamente", segundo os autores. Mesmo assim,

[...] os dois [Mário Quintana e Lupicínio Rodrigues] apresentam mais de uma característica estética em comum, permitindo comparações que talvez revelem algo sobre a alma da cidade em que viveram. Por exemplo: os dois são melancólicos, marca que se vê numa série de poemas e canções, sem dificuldade. (FISCHER \& FISCHER, 2006, p. 49)

Ao se verificar na História o extermínio dos povos indígenas que ocorreu no Brasil, não é difícil reconhecer a melancolia como um traço distintivo na cultura indígena. Logo, estaria presente também nos grupos de carnaval que têm o índio como mote. Por outras razões, a poesia feita em Porto Alegre traz a melancolia como marca recorrente. Em interação, todas essas influências constroem, arrisco hipotetizar, uma tradição local e uma característica comum a boa parte da produção poética.

Para exemplificar, dois trechos de hinos das tribos apresentados nos últimos que mostram uma perceptível marca da melancolia. O primeiro, "O Sonho de Paraguassu", composição de Eugenio Silva de Alencar, apresentada pela tribo Os Comanches em 2012, simboliza bem, tanto na letra quanto em sua música, a mística em torno da lenda do português Diogo Álvares e da índia Paraguassú, eternizada pela tradição oral brasileira e pelo poema épico "Camaruru”, de Frei Santa Rita Durão, externando um sentimento melancólico.

\footnotetext{
Viu caravelas a afundar

O Caraíba se salvar

Uma mulher e uma criança

Com mais brilho que o luar

Ela pediu a Paraguassu

Que mandasse Caramuru

A todos resgatar

Pois era seu destino

$\mathrm{Na}$ aldeia, ir morar
}

\footnotetext{
* Mestrando em Letras-Literatura Brasileira/UFRGS. E-mail: jacksonraymundo@yahoo.com.br
} 
O outro exemplo é a canção "O Grande Tratado da Nação Xinguana”, autoria de Mário Bartochak e Cavaco, tema dos Guaianazes em 2013. O enredo narra a história de resistência dos povos do Xingu, no norte do Mato Grosso, que foram tema de filme de bastante repercussão no ano anterior ("Xingu", direção de Cao Hamburger). Na letra, há a clareza de quem é o "inimigo" e o lamento pela perda da fauna e da flora, causada pelo homem branco "falso, traiçoeiro / cheio de ambição".

\author{
Ecoaram os tambores \\ Lá no alto do Xingu \\ Quando ouviram-se os rumores \\ Que vieram de além-mar \\ Homens brancos pra roubar o nosso ouro \\ Dizimando nossas tribos (bis) \\ Nossa fauna e nossa flora \\ Este cruel inimigo \\ Tem que sair campo afora
}

Nas letras dos hinos, é comum a presença de elementos do gênero épico, repetindo o que ocorre no samba-enredo. Assim como na canção do desfile de escolas de samba, elementos como a heroicidade e a mitificação de personalidades, mitologia e povos são característicos nas tribos.

Diferentemente das escolas de samba, no entanto, nem sempre o herói tem trajetória ascendente, como geralmente ocorre na epopeia, e na maioria das vezes ele é um ente coletivo (tal como nas culturas indígenas), e não individual. Mesmo tratando de feitos históricos ou mitológicos, a epopeia pode abrir espaço para a expressão da subjetividade, que faz aparecer sentimentos como a melancolia. Como explica Donaldo Schüler (1992),

A epopeia narra a instável relação do homem com as circunstâncias, que podem assumir posição de sujeito. [...]

Os narradores percebem cedo que mundo não é só o espetáculo que se oferece aos olhos, mundo é também o choque das forças que sacodem o interior dos homens. Ao penetrar no estranho mundo subjetivo, os narradores o povoam com divindades impalpáveis, como o Sonho, a Memória, o Amor e a Ira. (SCHÜLER, 1992, p. 1011)

As "divindades impalpáveis" elencadas por Schüler (sonho, memória, amor e ira) são temas muito presentes na mitologia indígena. Consequentemente, as canções das tribos carnavalescas dificilmente deixam de abordar um ou mais desses itens em seus hinos.

* Mestrando em Letras-Literatura Brasileira/UFRGS. E-mail: jacksonraymundo@yahoo.com.br 
A "essência" do épico é assim sintetizada por Vassalo (1992):

O relato das façanhas (sobre)humanas e lendárias de alguém dotado de uma qualidade ou defeito exacerbado e único, inserido num campo semântico coerente porém restrito, identificado como paladino de uma verdade ou sistema de valores monolítico e aceito sem discussão, levando esta aceitação às últimas consequências. (VASSALLO, 1992, p. 85-86)

Ao delimitar uma história indígena e um povo específico para o seu enredo, é aquele povo e aquela história que serão realçados pela tribo, independente do nome que leve. No entanto, alguns elementos costumeiramente aparecem, tais como o nome da tribo, às vezes acompanhada de qualificativos como "nação", e as "tabas" (as sedes das entidades) - Taba de Urupá, para Os Comanches, e Taba de Ocã, para os Guaianazes. Essas ocorrências podem ser consideradas como enumeração, uma das convenções da poesia épica. As demais características basilares do épico - propósito, invocação, in media res e epíteto - também estão presentes em boa parte dos hinos das tribos carnavalescas (e em boa parte da mitologia indígena).

\section{Considerações finais:}

Em suma, as tribos carnavalescas representam uma manifestação cultural peculiar e resistente. Inovadoras e persistentes, criaram e mantêm vivo um gênero lítero-musical praticado só por elas, o hino de tribos, que porta características singulares e já influenciou outros ritmos.

Chamam a atenção, ainda, porque não saía das academias a aplicabilidade de uma experiência artística que desse conta, de forma simultânea, das três raças do "triângulo" de que falavam os pesquisadores da cultura brasileira, mas das comunidades da periferia urbana de Porto Alegre, uma capital na periferia do poder federal.

Há uma superposição de vozes: o enunciador é negro, o locutor é índio e a mediação (o lugar de onde são extraídas as histórias, ou seja, os livros e outras fontes escritas) em geral é branca. Nesta superposição de vozes e interferência de influências e origens, as tribos carnavalescas resistem, se criam e recriam ano a ano, mitificando histórias e desmistificando preconceitos.

* Mestrando em Letras-Literatura Brasileira/UFRGS. E-mail: jacksonraymundo@yahoo.com.br 


\section{REFERÊNCIAS BIBLIOGRÁFICAS:}

APPEL, Myrna Bier et al. As formas do épico: da epopeia sânscrita à telenovela. Porto Alegre: Movimento, 1992.

SCHÜLER, Donaldo. Definições do épico. P. 9-14.

VASSALLO, Ligia. A canção de gesta e o épico medieval. P. 83-

99.

FISCHER, Luís Augusto; FISCHER, Sérgio Luís. Mário Quintana: uma vida para a poesia. Ilustrações de Gabriel Demarchi. Porto Alegre: WS Editor, 2006. 88 p. (Série Depoimentos)

GALVÃO, Walnice Nogueira. Ao som do samba: uma leitura do carnaval carioca. São Paulo: Editora Fundação Perseu Abramo, 2009. 194 p.

CARNEIRO, Luiz Carlos da Cunha; DA SILVA, Gilberto Ferreira; DOS SANTOS, José Antônio (Org.). RS Negro: cartografias sobre a produção do conhecimento. $2^{\mathrm{a}}$ edição revista e ampliada. Porto Alegre: EDIPUCRS, 2010.

GERMANO, Iris. Carnavais de Porto Alegre: etnicidade e territorialidades negras no Sul do Brasil. p. 100-119

AVANCINI, Elsa Gonçalves. O sagrado na tradição africana e os cultos afro-brasileiros. p. 134-147

GERMANO, Iris. Rio Grande do Sul, Brasil e Etiópia: os negros e o carnaval de Porto Alegre nas décadas de 1930 e 40. 1999. 275 f. Dissertação (Mestrado em História). Instituto de Filosofia e Ciências Humanas, Universidade Federal do Rio Grande do Sul, Porto $\quad 1999 . \quad$ Alegre. Disponível em: http://www.lume.ufrgs.br/handle/10183/28110. Acesso em: 25 jul 2013

KRAWCYCZ, Flávio; GERMANO, Iris; POSSAMAI, Zita. Carnavais de Porto Alegre. Porto Alegre: Secretaria Municipal da Cultura, 1992. 66 p.

* Mestrando em Letras-Literatura Brasileira/UFRGS. E-mail: jacksonraymundo@yahoo.com.br 
KUSCHIK, Mateus Berger. Suingue, samba-rock e balanço: músicos, desafios e cenários. Porto Alegre: Medianiz, 2013. 216 p.

MUSSA, Alberto; SIMAS, Luiz Antonio. Samba de enredo: história e arte. Rio de Janeiro: Civilização Brasileira, 2010. 238 p.

PEREIRA, Amauri Mendes. Um raio em céu azul: reflexões sobre a política de cotas e a identidade nacional brasileira. Estudos afro-asiáticos [online]. 2003, vol.25, n.3 , p. 463-482.

SZUTMAN, Renato (Org.). Eduardo Viveiros de Castro. Rio de Janeiro: Beco do Azougue, 2008. 288 p. (Encontros)

TINHORÃO, José Ramos. História social da música popular brasileira. São Paulo: Ed. 34, 1998. 384 p.

VIVEIROS DE CASTRO, Eduardo. A inconstância da alma selvagem - e outros ensaios de antropologia. $2^{\text {a }}$ edição. São Paulo: Cosac Naify, 2011. 552 p.

\section{Fontes:}

- BATICUMBUM. Justificativas das tribos carnavalescas. Disponível em: http://www.baticumbum.com.br/2013/02/justificativas-das-tribos-carnavalescas.html Acesso em: 10 agosto 2013.

- PORTO NA FOLIA. Tribos Carnavalescas. Disponível em: https://sites.google.com/site/portonafolia/tribos-carnavalescas Acesso em: 10 agosto 2013.

- PREFEITURA DE PORTO ALEGRE. Tribos ultrapassam 60 anos de tradição no Carnaval. Disponível em: http://migre.me/fLj99. Acesso em: 25 julho 2013

- WIKIPEDIA. Nhanderuvuçu. Disponível em: http://pt.wikipedia.org/wiki/Nhanderuvu \%C3\%A7u. Acesso em: 2 agosto 2013.

* Mestrando em Letras-Literatura Brasileira/UFRGS. E-mail: jacksonraymundo@yahoo.com.br 